\title{
A cross-sectional study investigating the relationship between handgrip strength with multimorbidity in Korean adults: Findings from the Korea National Health and Nutrition Examination Survey (KNHANES) VI-VII (2014-2017)
}

\section{Mee-Ri Lee}

Korea institute of health and Environment

Sung Min Jung ( $\nabla$ sungmin@paik.ac.kr)

Inje University Ilsan Paik Hospital https://orcid.org/0000-0001-5346-7315

Research article

Keywords: Multimorbidity, Handgrip Strength, Age

Posted Date: June 19th, 2020

DOI: https://doi.org/10.21203/rs.3.rs-31691/v1

License: (c) (i) This work is licensed under a Creative Commons Attribution 4.0 International License. Read Full License

Version of Record: A version of this preprint was published at Medicine on January 8th, 2021. See the published version at https://doi.org/10.1097/MD.0000000000023994. 


\section{Abstract \\ Background}

To date research investigating the associations between handgrip strength and multimorbidity when stratifying by age and sex is limited. Furthermore, this is the first study in a Korean population, and the first to include adults $\geq 19$ years of age. Here we investigated the associations between handgrip strength and multimorbidity in Korean adults aged $\geq 19$ years.

\section{Methods}

In this cross-sectional study data from the Korean National Health and Nutrition Examination Survey were used. Multimorbidity was defined as having two or more chronic diseases. A total of 19,779 participants were eligible for the study (8,730 male and 11,409 female). We grouped and analysed participants based on age and sex (men and women aged 19-49 years, men and women aged 50-80 years) and examined the associations between handgrip strength and multimorbidity using multivariate logistic regressions using stratification by age, sex and body mass index (BMI).

\section{Results}

Multivariate logistic regressions revealed a significant inverse association irrespective of sex, between relative handgrip strength and multimorbidity. Participants with the lowest handgrip strength had a significantly higher odds ratio (OR) of multimorbidity (men aged $19-49$ years: 3.76 and aged $50-80$ years: 2.11 ; women aged $19-49$ years: 1.52 and aged $50-80$ years: 2.15 ) when compared to those with highest handgrip strength after adjusting for confounding variables. The highest OR was observed in men aged $19-49$ years with a $B M I \geq 25 \mathrm{~kg} / \mathrm{m}^{2}$.

\section{Conclusion}

In the current study we observed a significant inverse relationship between handgrip strength and multimorbidity in males and females with two or more chronic diseases. Male participants with a low handgrip strength aged between 19-49 years with a BMI $\geq 25 \mathrm{~kg} / \mathrm{m}^{2}$ may be at greater risk of multimorbidity. This study highlights the need for further longitudinal studies to investigate the effects of increasing handgrip strength combined with weight loss, as an effective strategy to reduce the incidence of multimorbidity

\section{Background}

Multimorbidity can be defined as the presence of two or more chronic diseases in the same individual that can be clinically managed using medication and other interventions, but not cured [1]. Age has a significant effect on the occurrence and incidence of multimorbidity, where $65 \%$ of $65-84$-year-old's had multimorbidity, when compared with $81.5 \%$ of people aged $\geq 85$ years in UK [2]. Previous research has demonstrated that patients with multimorbidity are twice as likely to suffer from depression[3], have poor health related quality of life [4] and an increased risk of mortality [5]when compared to those without multimorbidity.

Handgrip strength is commonly used as a measure of physical fitness and muscle strength, both of which are related with allcause, cardiovascular and cancer mortality [6]. We provided evidence to substantiate this, where we were observed associations between handgrip strength, type 2 diabetes [7], depression [8] and cardiovascular disease [9]. These data indicate that handgrip strength may be a useful, inexpensive and non-invasive method for assessing multimorbidity.

Poor handgrip strength is commonly associated with a myriad of health problems; however, to date there is a lack of populationbased studies investigating the associations between handgrip strength and multimorbidity. Two cross-sectional studies in HongKong [10] and Brazil [11] both identified that men with a low handgrip strength were more likely to have multimorbidity, which was not the case in women. Contrastingly, a cross-sectional study in Germany observed that lower handgrip strength was significantly associated with multimorbidity among women but not in men [12]. Interestingly, to date previous research surrounding sex specific 
analysis on handgrip strength and multimorbidity have reported inconsistent results. Furthermore, some studies using handgrip strength have failed to correct for body mass index (BMI) and weight and are not a true representation of a national data. Finally, to the best of our knowledge, there are few studies in subjects under the age of 50 years, and the effects of BMI on handgrip strength and multimorbidity remains poorly understood.

Therefore, the primary aim of the present study was to examine the association between handgrip strength and multimorbidity in a population-based data generated from the Korean National Health and Nutrition Examination Survey (KNHANES).

\section{Methods}

This is a cross-sectional study design of the Korean population from the KNHANES, an annual study that has been conducted since 2007. The study targets only Koreans and is based on a complex stratified multistage probability cluster survey of a crosssectional and nationally representative sample of individuals from the non-institutionalized civilian population by the Division of Chronic Disease Surveillance, Korea Centres for Disease Control and Prevention.

Data from the KNHANES VI-VII (2014-2017), including data relating to handgrip strength was included. Participants were excluded from the study if they were $<19$ years of age $(n=6,386)$, provided insufficient information of questionnaires relating to multimorbidity $(n=2,975)$, and had no measurement of handgrip strength for the right or left hand $(n=2,067)$. Following exclusion of these participants, a total of 19,779 participants (male: 8,730 , female: 11,049) remained that were eligible for the study (Fig. 1).

Definitions of multimorbidity

The KNHANES VI-VII questionnaires included 25 chronic diseases (hypertension, dyslipidaemia, stroke, myocardial infarction, angina, osteoarthritis, rheumatic arthritis, tuberculosis, asthma, allergic rhinitis, depression, kidney failure, atopic dermatitis, diabetes mellitus, thyroid disease, stomach cancer, liver cancer, colon cancer, breast cancer, cervical cancer, lung cancer, thyroid cancer, liver cirrhosis, hepatitis B, and hepatitis C). The presence of chronic disease was confirmed by a clinician and confirmed by participants using self-reports. Participants also reported if they still had the disease or if the disease had been treated.

Participants were defined as multimorbidity if they had two of more confirmed chronic diseases.

Measurement of handgrip strength

Handgrip strength was measured three times in each hand, using a digital grip strength dynamometer (TKK 5401; Takei Scientific Instruments Co., Ltd., Tokyo, Japan). Trained medical technicians instructed participants to hold the dynamometer with the distal interphalangeal finger joints of the hand at $90^{\circ}$ to the handle and to squeeze the handle as firmly as they could whilst being seated. After participants had slowly stood up, handgrip strength was measured during expiration. Study participants conducted three attempts per hand, with a one-minute rest period between each attempt to reduce the effects of fatigue. Handgrip strength of the participants' dominant hand was defined using questionnaires, and an average of the three measurements was used [13]. Relative handgrip strength was defined as grip strength per unit of BMI.

Covariates

The self-reported questionnaire provided information relating to participants education, smoking status, alcohol consumption, and physical activity. As education levels are lower in the elderly, education was divided into two categories of $\leq 9$ and $>9$ years of school. Smoking status was classified as never smoking, former smokers and currently smoking. Current smokers self-reported that they smoked > 100 cigarettes in their lifetime and were currently still smoking. Past smokers self-reported that they had a history of smoking. Participants who consumed alcohol were defined as those who drink at least one glass of alcohol every month over the last year. Physically activity participants were defined as those who had performed exercise for least 150 minutes per week at a moderate intensity (fast walking, carrying light objects, cleaning, parenting, etc.); 75 minutes per week at a high intensity (lifting or carrying heavy items, digging, labor at construction sites, carrying objects on stairs) (or a combination of medium and high-intensity physical activity (where one minute of high-intensity activity = two minutes of medium intensity activity). BMI was calculated as weight divided by height squared $\left(\mathrm{kg} / \mathrm{m}^{2}\right)$.

Statistical analyses

Page $3 / 12$ 
Statistical guidance was provided by the Korean Centre for Disease Control and Prevention, raw data from the VI-VII (2014-2017) were combined and complex sample analysis was utilised using the weighting data from KNHANES. Sex and age were used to divide participants when investigating associated between handgrip strength and multimorbidity. The groups utilised were 19-49 and $50-80$ years old, for both male and female participants.

Differences in demographic and anthropometric characteristics were compared using the Student's t-test or Chi-square test, as appropriate. Complex sample multivariate logistic regression was performed to analyse the relationship between relative handgrip strength and multimorbidity, and odds ratio (OR) and 95\% confidence intervals (Cl) were calculated. Model 1 adjusted for age and Model 2 adjusted for age, education ( $\leq 9,>9$ years of school), alcohol consumption (yes vs. no), smoking status (never, former, current), and physical activity (yes vs. no). Relative handgrip strength was divided into quartiles. ORs were calculated using complex samples logistic regression analysis to examine associations between the quartile of relative handgrip strength and the presence of multimorbidity based on the highest quartile. Logistic regression analysis was repeated for all age groups using a stratified approach with a BMl $<25 \mathrm{~kg} / \mathrm{m}^{2}$ and a BMI $\geq 25 \mathrm{~kg} / \mathrm{m}^{2}$. Statistical significance was defined as $P<0.05$. Continuous and categorical variables were expressed as mean \pm standard deviation ( $\pm \mathrm{SD})$ and number $(\mathrm{n})(\%)$, respectively. All statistical analysis were performed using SPSS software (IBM Corp. Released 2017. IBM SPSS Statistics

for Windows, Version 25.0. Armonk, NY: IBM Corp). All graphical representations were prepared using the R software suite, version 3.3.3 (The Comprehensive R Archive Network: http://cran.r-project.org).

\section{Results}

A total of 19,779 participants were included in the study, of which there were 4075:5256 (male:female) 19-49 year olds, and 4655:5793 (male:female) aged 50-80 years. The mean ( \pm SD) age of the 19-49 years old, and 50-80 years, was 35.67( \pm 8.69$)$ years old (male: $35.53( \pm 8.74)$, female: $35.77( \pm 8.66)$ ), and $64.28( \pm 9.02)$ years old (male: $64.44( \pm 8.87)$, female: $64.15( \pm 9.13)$ ), respectively.

In all participants, $21.86 \%$ reported as having two or more chronic diseases with the mean number of chronic disease in multimorbidity participants being $2.68( \pm 1.01)$.

The proportion of participants with multimorbidity increased with age, where $19-49$ year old's had $5.66 \%$ compared to $36.32 \%$ in 50-80-year- olds.

The proportion of females with multimorbidity was higher when compared with males in the 50-80 years olds (female vs. male: $40.17 \%$ vs. $31.54 \%$ ). In contrast, in the 19-49 age group, male participants had a higher proportion of multimorbidity when compared with females $(6.21 \%$ vs. $5.23 \%$, respectively).

Age, education, smoking status, alcohol consumption, physical activity, number of chronic diseases and dominant handgrip strength were significantly different between sexes in the 50-80-year-old group (Table 1). Similar findings were observed in the 1949-year-old group; however, age and education were not significantly different (Table 1). After adjusting for age, education, physical activity, smoking status, alcohol consumption, relative handgrip strength were inversely associated with multimorbidity in both men and women in both age groups (Table 2). 
Table 1

Participants' sociodemographic and clinical characteristics by sex and age group.

\begin{tabular}{|c|c|c|c|c|c|c|c|c|}
\hline Variable & $19-49$ & & & & $50-80$ & & & \\
\hline & Men & Women & Total & $\begin{array}{l}\mathrm{p}- \\
\text { value }\end{array}$ & Men & Women & Total & $\begin{array}{l}\mathrm{p}- \\
\text { value }\end{array}$ \\
\hline $\mathrm{n}$ & 4,075 & 5,256 & 9,331 & & 4,655 & 5,793 & 10,448 & \\
\hline Age & $35.53(8.74)$ & $35.77(8.66)$ & $35.67(8.69)$ & 0.202 & $64.44(8.87)$ & 64.15(9.13) & 64.28(9.02) & $\begin{array}{l}<.001 \\
0.00\end{array}$ \\
\hline \multicolumn{9}{|l|}{ Education } \\
\hline$<9$ years & 162(3.92) & 203(3.87) & $365(3.90)$ & 0.91 & $2093(40.46)$ & $3702(60.71)$ & $5798(50.92)$ & $\begin{array}{l}<.001 \\
0.00\end{array}$ \\
\hline$\geq 9$ years & $3902(96.08)$ & $5047(96.13)$ & $8949(96.10)$ & & 2521(59.54) & $2037(39.29)$ & $4558(49.08)$ & \\
\hline Not response & 11 & 6 & 17 & & 38 & 54 & 92 & \\
\hline \multicolumn{9}{|l|}{$\begin{array}{l}\text { Smoking } \\
\text { status }\end{array}$} \\
\hline $\begin{array}{l}\text { Never } \\
\text { smoker }\end{array}$ & 1186(30.52) & $4471(84.82)$ & $5657(56.81)$ & <. 001 & $858(18.35)$ & $5355(93.44)$ & $6213(57.15)$ & $\begin{array}{l}<.001 \\
0.00\end{array}$ \\
\hline $\begin{array}{l}\text { Former } \\
\text { smoker }\end{array}$ & 1081(25.59) & $451(8.54)$ & 1532(17.33) & & $2464(51.58)$ & 188(3.19) & $2652(26.58)$ & \\
\hline $\begin{array}{l}\text { Current } \\
\text { smoker }\end{array}$ & 1794(43.89) & $327(6.64)$ & $2121(25.86)$ & & $1279(30.06)$ & 169(3.36) & 1448(16.27) & \\
\hline Not response & 14 & 7 & 21 & & 54 & 81 & 135 & \\
\hline \multicolumn{9}{|l|}{$\begin{array}{l}\text { Alcohol } \\
\text { consumption }\end{array}$} \\
\hline Non-drinker & $883(21.86)$ & $2333(43.85)$ & $3216(32.51)$ & $\dot{0} 001$ & 1551(31.11) & $4145(70.54)$ & $5696(51.49)$ & $\begin{array}{l}<.001 \\
0.00\end{array}$ \\
\hline $\begin{array}{l}\text { Alcohol } \\
\text { drinker }\end{array}$ & $3178(78.14)$ & 2916(56.15) & 6094(67.49) & & $3054(68.89)$ & $1574(29.46)$ & $4628(48.51)$ & \\
\hline Not response & 14 & 7 & 21 & & 50 & 74 & 124 & \\
\hline \multicolumn{9}{|l|}{$\begin{array}{l}\text { Physical } \\
\text { activity }\end{array}$} \\
\hline No & 1708(40.79) & $2535(46.48)$ & $4243(43.54)$ & <. 001 & $2565(53.43)$ & $3609(61.13)$ & $6174(57.40)$ & $\begin{array}{l}<.001 \\
0.00\end{array}$ \\
\hline Yes & $2350(59.21)$ & $2710(53.52)$ & $5060(56.46)$ & & $2047(46.57)$ & 2112(38.87) & $4159(42.60)$ & \\
\hline Not response & 17 & 11 & 28 & & 43 & 72 & 115 & \\
\hline \multicolumn{9}{|l|}{$\begin{array}{l}\text { Number of } \\
\text { chronic } \\
\text { disease }\end{array}$} \\
\hline 0 & $2972(73.40)$ & $3653(69.05)$ & $6625(71.30)$ & $\dot{0} 001$ & $1781(42.08)$ & 1783(33.37) & $3564(37.57)$ & $\begin{array}{l}<.001 \\
0.00\end{array}$ \\
\hline 1 & $850(20.72)$ & $1328(25.64)$ & $2178(23.10)$ & & $1406(29.56)$ & $1683(29.64)$ & $3089(29.60)$ & \\
\hline
\end{tabular}

Chi-squared test was used for categorical variable. And Student $t$ test was used for continuous variables.

$\mathrm{BMI}=$ body mass index

Significant values were expressed in bold. 


\begin{tabular}{|c|c|c|c|c|c|c|c|c|}
\hline Variable & $19-49$ & & & & $50-80$ & & & \\
\hline 2 & 203(4.69) & $221(4.34)$ & $424(4.52)$ & & $829(16.28)$ & 1215(19.74) & $2044(18.07)$ & \\
\hline 3 & $42(1.01)$ & $44(0.77)$ & $86(0.89)$ & & 404(7.87) & $680(10.48)$ & 1084(9.22) & \\
\hline $4+$ & $8(0.18)$ & $10(0.20)$ & 18(0.19) & & $235(4.22)$ & $432(6.77)$ & $667(5.54)$ & \\
\hline $\begin{array}{l}\text { Dominant } \\
\text { hand }\end{array}$ & $41.65(7.34)$ & $24.44(4.77)$ & $31.95(10.45)$ & $\hat{0} .001$ & $35.08(7.78)$ & $21.20(5.26)$ & 27.38(9.48) & <. 001 \\
\hline $\begin{array}{l}\text { Dominant } \\
\text { hand/BMI }\end{array}$ & $1.71(0.34)$ & $1.10(0.24)$ & $1.37(0.42)$ & $\hat{0} .001$ & $1.47(0.33)$ & $0.89(0.24)$ & $1.15(0.41)$ & $<.001$ \\
\hline \multicolumn{9}{|l|}{ BMI } \\
\hline$<25$ & 2337(58.4) & $4146(79.45)$ & 6483(68.57) & $\hat{0} .001$ & 2945(61.95) & $3597(63.06)$ & $6542(62.52)$ & 0.332 \\
\hline$\geq 25$ & 1738(41.6) & $1110(20.55)$ & 2848(31.43) & & $1710(38.05)$ & 2196(36.94) & $3906(37.48)$ & \\
\hline \multicolumn{9}{|c|}{ Chi-squared test was used for categorical variable. And Student $t$ test was used for continuous variables. } \\
\hline \multicolumn{9}{|c|}{$\mathrm{BMI}=$ body mass index } \\
\hline \multicolumn{9}{|c|}{ Significant values were expressed in bold. } \\
\hline
\end{tabular}

Table 2

Multivariate logistic regression associations between continuous relative handgrip strength and multimorbidity.

\begin{tabular}{|c|c|c|c|c|c|}
\hline & \multirow[b]{2}{*}{$\mathrm{N}$} & \multicolumn{2}{|l|}{ Model 1} & \multicolumn{2}{|l|}{ Model 2} \\
\hline & & $\mathrm{OR}(95 \% \mathrm{Cl})$ & $P$ value & $\mathrm{OR}(95 \% \mathrm{Cl})$ & $P$ value \\
\hline \multicolumn{6}{|l|}{$19-49$} \\
\hline Men & 4,075 & $0.21(0.14,0.33)$ & $<0.001$ & $0.24(0.15,0.38)$ & $<0.001$ \\
\hline Women & 5,256 & $0.48(0.24,0.92)$ & 0.028 & $0.47(0.24,0.91)$ & 0.026 \\
\hline \multicolumn{6}{|l|}{$50-80$} \\
\hline Men & 4,655 & $0.38(0.29,0.49)$ & $<0.001$ & $0.40(0.31,0.52)$ & $<0.001$ \\
\hline Women & 5,793 & $0.24(0.18,0.34)$ & $<0.001$ & $0.25(0.18,0.35)$ & $<0.001$ \\
\hline \multicolumn{6}{|c|}{$\mathrm{BMI}=$ body mass index, $\mathrm{Cl}=$ confidence interval, $\mathrm{OR}=$ odds ratio } \\
\hline
\end{tabular}

In participants with the lowest quartile of handgrip strength, the ORs of having multimorbidity was 3.76 (19-49 years) and 2.11 (50-80 years) compared to those with the highest quartile for males. Among female participants who had lowest quartile of handgrip strength, ORs were 1.52 (19-49 years) and 2.15 (50-80 years) compared to those in the highest quartile. Male participants had a higher OR than females across all ages, whereas the largest OR was reported in the 19-49-year-old age group, whereas female participants were similar across all ages (Fig. 2).

In men $<50$, the association between handgrip strength and multimorbidity was significantly higher in participants with a BMI $\geq$ $25 \mathrm{~kg} / \mathrm{m}^{2}$. In men $>50$ years old participants with a BMl $<$ and $\geq 25 \mathrm{~kg} / \mathrm{m}^{2}$ were significant. (Table 3 ) 
Table 3

Multivariate logistic regression association between quartile of relative handgrip strength and multimorbidity using stratified analysis by body mass index.

\begin{tabular}{|c|c|c|c|c|c|c|c|c|}
\hline \multirow[t]{2}{*}{ Age } & \multirow[t]{2}{*}{ Sex } & \multirow[b]{2}{*}{ Quartile } & \multicolumn{3}{|c|}{$\mathrm{BMI}\left(<25 \mathrm{~kg} / \mathrm{m}^{2}\right)$} & \multicolumn{3}{|c|}{$\mathrm{BMI}\left(\geq 25 \mathrm{~kg} / \mathrm{m}^{2}\right)$} \\
\hline & & & OR & $95 \% \mathrm{Cl}$ & $\mathrm{p}$ value & OR & $95 \% \mathrm{Cl}$ & $P$ value \\
\hline \multirow[t]{8}{*}{$19-49$} & Men & $4 Q$ & 1 & & & 1 & & \\
\hline & & $3 Q$ & 1.00 & $(0.51,1.97)$ & 0.996 & 2.74 & $(0.86,8.74)$ & 0.089 \\
\hline & & $2 Q$ & 1.16 & $(0.59,2.26)$ & 0.672 & 3.47 & $(1.12,10.76)$ & 0.031 \\
\hline & & $1 \mathrm{Q}$ & 1.86 & $(0.87,3.97)$ & 0.107 & 5.65 & $(1.88,16.93)$ & 0.002 \\
\hline & Women & $4 Q$ & 1 & & & 1 & & \\
\hline & & $3 Q$ & 0.96 & $(0.55,1.41)$ & 0.604 & 0.88 & $(0.29,3.21)$ & 0.951 \\
\hline & & $2 Q$ & 0.30 & $(0.66,1.65)$ & 0.861 & 1.04 & $(0.09,1.00)$ & 0.05 \\
\hline & & $1 \mathrm{Q}$ & 0.89 & $(0.77,2.00)$ & 0.376 & 1.24 & $(0.31,2.58)$ & 0.837 \\
\hline \multirow[t]{8}{*}{$50-80$} & Men & $4 Q$ & 1 & & & 1 & & \\
\hline & & $3 Q$ & 1.31 & $(1.00,1.73)$ & 0.052 & 1.24 & $(0.83,1.87)$ & 0.298 \\
\hline & & $2 Q$ & 1.80 & $(1.37,2.37)$ & $<0.001$ & 1.68 & $(1.12,2.53)$ & 0.013 \\
\hline & & $1 \mathrm{Q}$ & 1.92 & $(1.39,2.63)$ & $<0.001$ & 1.73 & $(1.14,2.63)$ & 0.01 \\
\hline & Women & $4 Q$ & 1 & & & 1 & & \\
\hline & & $3 Q$ & 1.34 & $(1.07,1.67)$ & 0.01 & 1.20 & $(0.78,1.84)$ & 0.41 \\
\hline & & $2 Q$ & 1.69 & $(1.31,2.18)$ & $<0.001$ & 1.35 & $(0.88,2.06)$ & 0.165 \\
\hline & & $1 \mathrm{Q}$ & 1.48 & $(1.09,2.02)$ & 0.013 & 1.43 & $(0.93,2.21)$ & 0.102 \\
\hline \multicolumn{9}{|c|}{$\mathrm{BMI}=$ body mass index, $\mathrm{Cl}=$ confidence interval, $\mathrm{OR}=$ odds ratio, $\mathrm{Q}=$ quartile. } \\
\hline & & & & Son drintri & Dhor & & & \\
\hline
\end{tabular}

\section{Discussion}

The primary aim of the present study was to examine the association between handgrip strength and multimorbidity in a population-based data generated from the Korean National Health and Nutrition Examination Survey (KNHANES). In our study, we observed that the prevalence of multimorbidity increased with age and the proportion of female participants with multimorbidity was higher than male participants aged $\geq 50$ years. Similar findings have previously been reported, where an S-shaped curve was observed for prevalence by age [14]. In the US National Health and Nutrition Examination Survey (NHANES), multimorbidity was higher in female than male participants, and in all adults aged $\geq 20,60 \%$ had two or more multimorbidities compared with $92 \%$ in participants aged $\geq 65$ years old from 11 possible conditions [15].

The data presented here confirms previously published literature, where handgrip strength and multimorbidity are related when stratifying the analysis by age and sexgender. However, we were not able to find any effect of sex alone in the general Korean population. The data presented here confirms previously published literature, where handgrip strength and multimorbidity are related when stratifying the analysis by age and gender. However, we were not able to find any effect of gender alone in the general Korean population. Two previously published cross-sectional studies by Cheung et al. [10] and Amaral et al. [11] in Hong Kong and Brazil, respectively, reported that handgrip strength was an effective marker for identifying male participants with multimorbidity, which may have been due to sex-related hormone differences as no association was observed in females. Contrastingly, Volaklis et al. [12] reported that in a German population handgrip strength was inversely and independently associated with multimorbidity in women $\geq 65$ years of age, but not in men. However, in a recent Brazilian study, men without 
myopenia aged $>60$ years with a low handgrip strength were more likely to have multimorbidity [16]. Furthermore, in a recent cross-sectional study conducted across six countries (China, Ghana, India, Mexico, Russia, South Africa), the authors failed to report any sex associations in adults $>50$ years of age, but did report an association between low handgrip strength and an increasing number of chronic conditions [17].

Several biological mechanisms have been reported that may be responsible for the relationship between handgrip strength and multimorbidity. For example, the production and release of several cytokines and peptides from skeletal muscle during contractions termed 'myokines' has been associated with metabolic pathways, body fat regulation, anti-inflammatory effects, improved insulin sensitivity, suppression of tumour growth and improved cognitive function [18]. Previous research from our group has also demonstrated a relationship between handgrip strength and the inflammatory marker high sensitivity C-reactive protein [9] Furthermore, reactive oxygen species produced by skeletal muscle are increased during exercise, leading to increased expression of antioxidants [19]. In chronic degenerative diseases such as chronic obstructive pulmonary disease, chronic cardiovascular disease, metabolic diseases, and neurodegeneration have all been shown to be affected by chronic oxidative stress. [20], suggesting a potential protective effect of exercise

The findings presented here demonstrate that males in the 19-49 years old group with a BMI $\geq 25 \mathrm{~kg} / \mathrm{m}^{2}$ combined with a low handgrip strength had the highest OR. Supporting these findings, in a Canadian study population, the incidence of multimorbidity was higher in obese participants, but not in those with normal BMI [21]. Obesity and a lack of physical activity have previously been identified to be a significant predictor of multimorbidity in adults aged $>55$ years in New Zealand [22]. Furthermore, in a cohort study from Iran, obese participants had an OR that was 2.33-fold higher than participants with a normal BMI [23]. Obesity is a well-established risk factor for chronic diseases, and has been shown to cause systemic inflammation and activate well-known pathways for cancer, cardiovascular disease and type 2 diabetes mellitus [24]. The results from the current study amongst others may provide the basis for further management of participants with a high BMI and low handgrip strength for the early onset of non-communicable diseases and multimorbidity.

The present study has several important strengths. Firstly, this is the first study to investigate the relationship between handgrip strength and multimorbidity in a large nationally representative sample size from Korea. Secondly, we were able to stratify the analysis between handgrip strength and multimorbidity by age and gender. Thirdly, this is the first study to investigate the impact of handgrip strength on multimorbidity in adults between 19 and 80 years of age. Finally, we were able to identify that a combination of an increased BMI and low handgrip strength had a more pronounced effect on multimorbidity in 19-49-year-olds.

This study is not without limitations. Firstly, all participants were Korean, meaning that our findings cannot be extrapolated to other ethnicities. Secondly, information relating to medical conditions was based on self-reporting questionnaires, which may cause recall biases. Finally, this study is cross-sectional and any attempt to determine causality or temporality in the association between handgrip and multimorbidity is not possible.

\section{Conclusion}

In the current study we observed a significant inverse relationship between handgrip strength and multimorbidity in males and females with two or more chronic diseases. Male participants with a low handgrip strength aged between 19-49 years with a BMI $\geq 25 \mathrm{~kg} / \mathrm{m}^{2}$ may be at greater risk of multimorbidity. This study highlights the need for further longitudinal studies to investigate the effects of increasing handgrip strength combined with weight loss, as an effective strategy to reduce the incidence of multimorbidity.

\section{Abbreviations}

BMI: body mass index $\mathrm{Cl}=$ confidence interval, $\mathrm{KNHANES}=$ Korean National Health and Nutrition Examination Survey, OR $=$ odds ratio, $\mathrm{SD}=$ standard deviation

\section{Declarations}


Ethics approval and consent to participate:

Our study protocol was approved by the institutional review board of the ethics committee of Ilsan-paik hospital (approval number: ISPAIK 2020-05-022).

\section{Consent for publication:}

Not applicable.

\section{Availability of data and materials:}

The data from KNHANES is available on request by email by visiting the Korea National Health and Nutrition Examination Survey website (http://knhanes.cdc.go.kr) and is free of charge for the purposes of academic research.

\section{Competing interests:}

The authors have no relevant potential conflicts of interest to disclose.

\section{Authors' contributions:}

All authors involved in the conceptualization and design of the study. MRL carried out the analysis. All authors contributed to the manuscript. The final version of the manuscript was read and approved by all authors.

\section{Acknowledgements:}

This work was supported by the 2018 Inje University research grant. We thank our colleagues from Department of surgery, Ilsanpaik hospital who provided insight and expertise that greatly assisted the research, although they may not agree with all of the interpretations/conclusions of this paper.

\section{Authors' information (optional):}

${ }^{1}$ Korea institute of Health \& Environment, 87, Seongsui-ro, Seongdong-gu, Seoul, Republic of Korea. ${ }^{2}$ Department of Surgery, Inje Univ. Ilsan Paik Hospital, 170 Juhwa-ro, IlsanSeo-gu, Goyang-si, Gyeonggi-do, 10380, Republic of Korea

\section{References}

1. Yarnall AJ, Sayer AA, Clegg A, Rockwood K, Parker S, Hindle JV. New horizons in multimorbidity in older adults. Age Ageing. 2017;46(6):882-8.

2. Barnett K, Mercer SW, Norbury M, Watt G, Wyke S, Guthrie B. Epidemiology of multimorbidity and implications for health care, research, and medical education: a cross-sectional study. Lancet. 2012;380(9836):37-43.

3. Read JR, Sharpe L, Modini M, Dear BF. Multimorbidity and depression: A systematic review and meta-analysis. J Affect Disord. 2017;221:36-46.

4. Kanesarajah J, Waller M, Whitty JA, Mishra GD. Multimorbidity and quality of life at mid-life: A systematic review of general population studies. Maturitas. 2018;109:53-62.

5. Nunes BP, Flores TR, Mielke GI, Thume E, Facchini LA. Multimorbidity and mortality in older adults: A systematic review and meta-analysis. Arch Gerontol Geriatr. 2016;67:130-8.

6. Yates T, Zaccardi F, Dhalwani NN, Davies MJ, Bakrania K, Celis-Morales CA, Gill JMR, Franks PW, Khunti K. Association of walking pace and handgrip strength with all-cause, cardiovascular, and cancer mortality: a UK Biobank observational study. Eur Heart J. 2017;38(43):3232-40.

7. Lee MR, Jung SM, Bang H, Kim HS, Kim YB. Association between muscle strength and type 2 diabetes mellitus in adults in Korea: Data from the Korea national health and nutrition examination survey (KNHANES) VI. Medicine. 2018;97(23):e10984.

8. Lee MR, Jung SM, Bang H, Kim HS, Kim YB. The association between muscular strength and depression in Korean adults: a cross-sectional analysis of the sixth Korea National Health and Nutrition Examination Survey (KNHANES VI) 2014. BMC 
Public Health. 2018;18(1):1123.

9. Lee MR, Jung SM, Kim HS, Kim YB. Association of muscle strength with cardiovascular risk in Korean adults: Findings from the Korea National Health and Nutrition Examination Survey (KNHANES) VI to VII (2014-2016). Medicine.

2018;97(47):e13240.

10. Cheung CL, Nguyen US, Au E, Tan KC, Kung AW. Association of handgrip strength with chronic diseases and multimorbidity: a cross-sectional study. Age (Dordrecht Netherlands). 2013;35(3):929-41.

11. Amaral Cde A, Portela MC, Muniz PT, Farias Edos S, Araujo TS, Souza OF. Association of handgrip strength with self-reported diseases in adults in Rio Branco, Acre State, Brazil: a population-based study. Cadernos de saude publica. 2015;31(6):131325.

12. Volaklis KA, Halle M, Thorand B, Peters A, Ladwig KH, Schulz H, Koenig W, Meisinger C. Handgrip strength is inversely and independently associated with multimorbidity among older women: Results from the KORA-Age study. European journal of internal medicine. 2016;31:35-40.

13. Roberts HC, Denison HJ, Martin HJ, Patel HP, Syddall H, Cooper C, Sayer AA. A review of the measurement of grip strength in clinical and epidemiological studies: towards a standardised approach. Age Ageing. 2011;40(4):423-9.

14. Fortin M, Stewart M, Poitras M-E, Almirall J, Maddocks H. A systematic review of prevalence studies on multimorbidity: toward a more uniform methodology. Ann Fam Med. 2012;10(2):142-51.

15. King DE, Xiang J, Pilkerton CS. Multimorbidity Trends in United States Adults, 1988-2014. J Am Board Fam Med. 2018;31(4):503-13.

16. Montes MC, Bortolotto CC, Tomasi E, Gonzalez MC, Barbosa-Silva TG, Domingues MR, Bielemann RM. Strength and multimorbidity among community-dwelling elderly from southern Brazil. Nutrition (Burbank Los Angeles County Calif). 2019;71:110636.

17. Vancampfort D, Stubbs B, Firth J, Koyanagi A. Handgrip strength, chronic physical conditions and physical multimorbidity in middle-aged and older adults in six low- and middle income countries. European journal of internal medicine. 2019;61:96102.

18. Hoffmann C, Weigert C. Skeletal Muscle as an Endocrine Organ: The Role of Myokines in Exercise Adaptations. Cold Spring Harb Perspect Med. 2017;7(11):a029793.

19. Steinbacher P, Eckl P. Impact of oxidative stress on exercising skeletal muscle. Biomolecules. 2015;5(2):356-77.

20. Barnes PJ. Mechanisms of development of multimorbidity in the elderly. Eur Respir J. 2015;45(3):790-806.

21. Lebenbaum M, Zaric GS, Thind A, Sarma S. Trends in obesity and multimorbidity in Canada. Preventive medicine. 2018;116:173-9.

22. Aminisani N, Stephens C, Allen J, Alpass F, Shamshirgaran SM. Socio-demographic and lifestyle factors associated with multimorbidity in New Zealand. Epidemiology health. 2020;42:e2020001.

23. Ahmadi B, Alimohammadian M, Yaseri M, Majidi A, Boreiri M, Islami F, Poustchi H, Derakhshan MH, Feizesani A, Pourshams A, et al. Multimorbidity: Epidemiology and Risk Factors in the Golestan Cohort Study, Iran: A Cross-Sectional Analysis. Medicine. 2016;95(7):e2756-6.

24. Freisling H, Viallon V, Lennon H, Bagnardi V, Ricci C, Butterworth AS, Sweeting M, Muller D, Romieu I, Bazelle P, et al. Lifestyle factors and risk of multimorbidity of cancer and cardiometabolic diseases: a multinational cohort study. BMC Med.

2020;18(1):5.

\section{Figures}




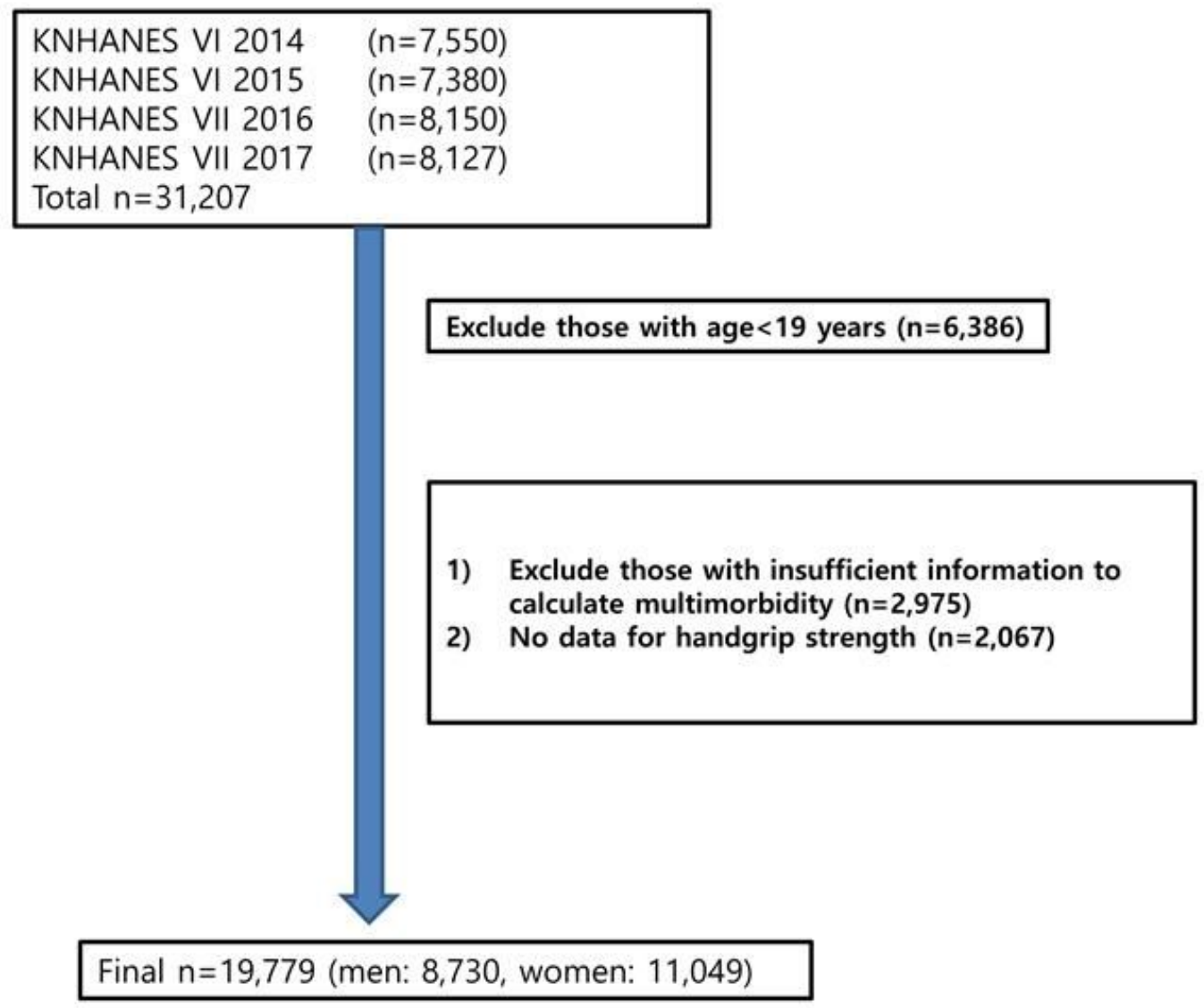

Figure 1

Participant flow diagram illustrating the number of patients excluded by various criteria, and the number of patient data sets analysed. 


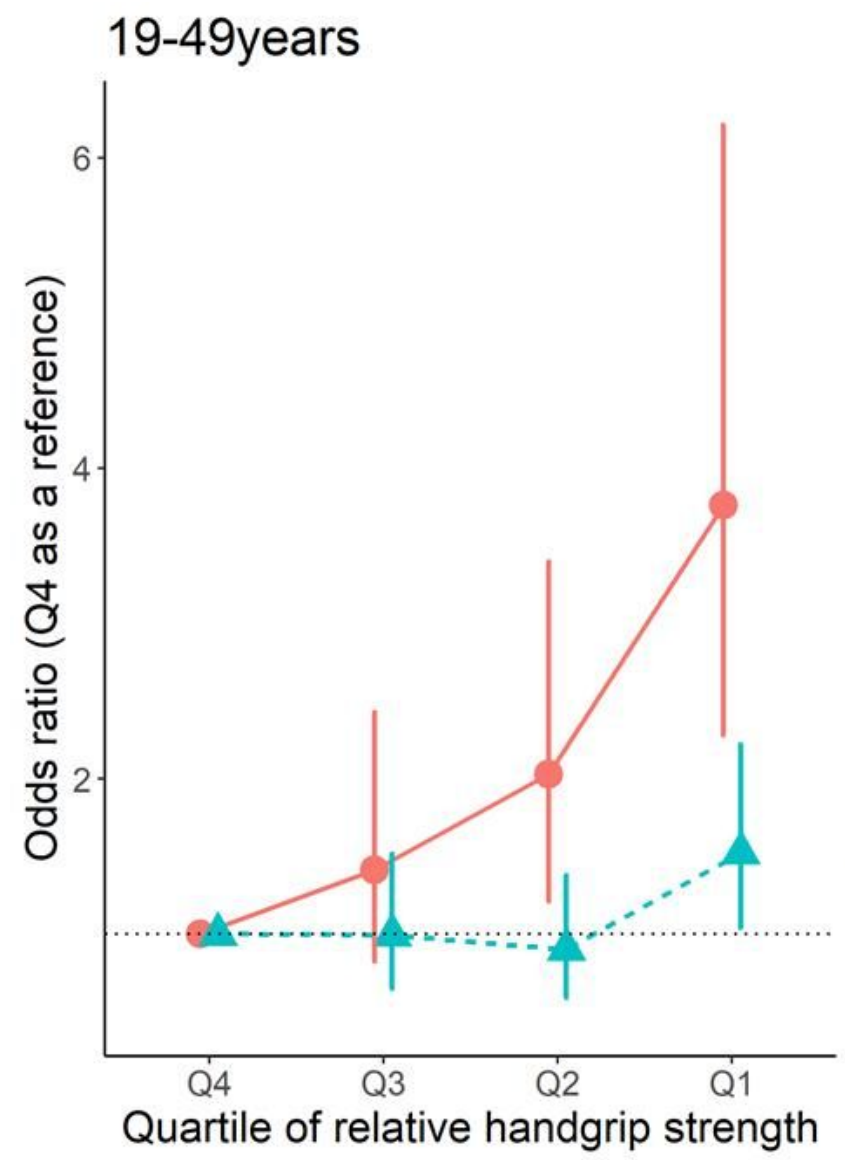

50-80years

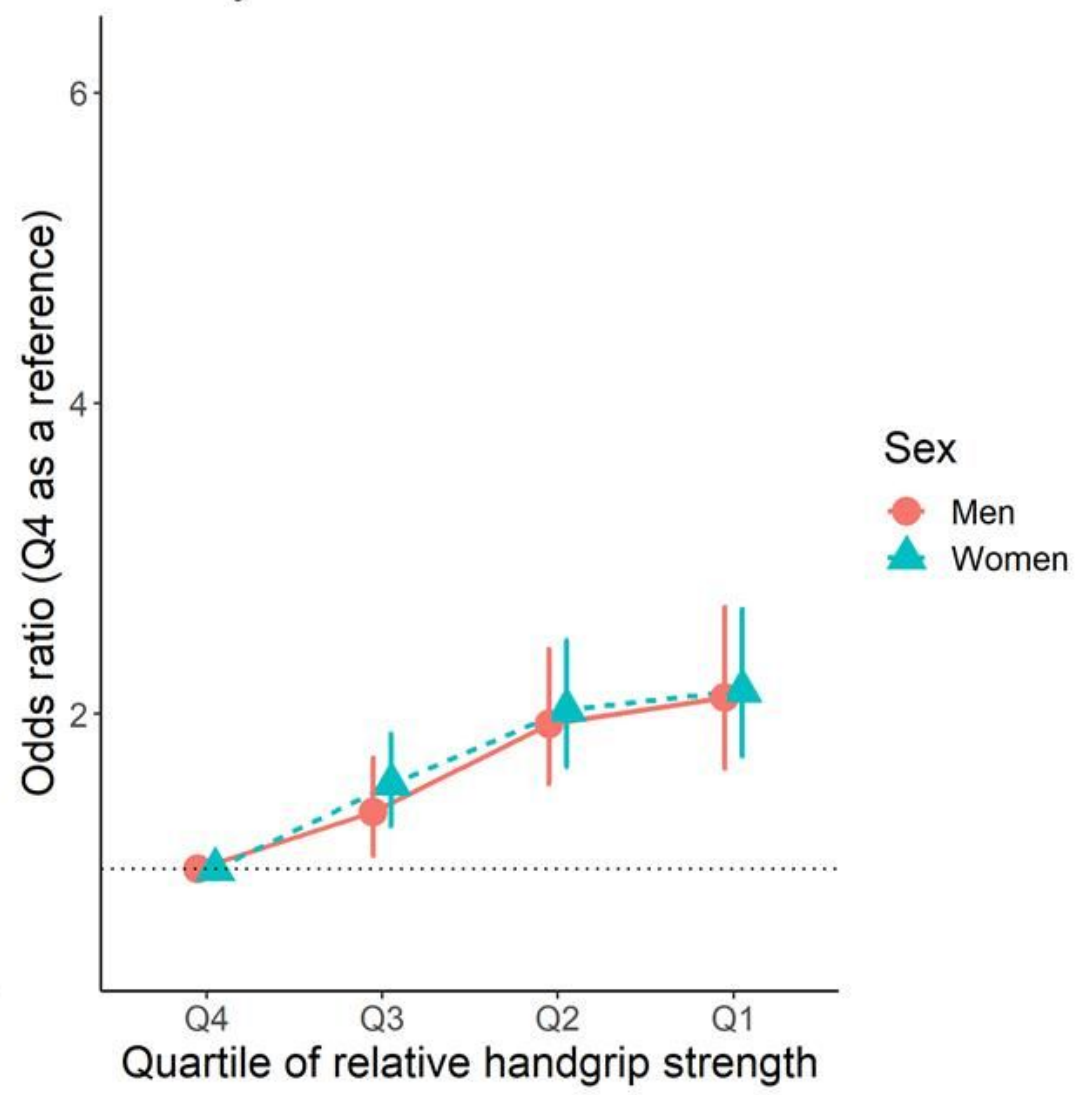

Figure 2

Multivariate logistic regression association between relative handgrip strength quartile and risk of multimorbidity. The analysis was adjusted for age, education, alcohol consumption, smoking status, and physical activity. 